\title{
Physiological and Productivity Responses of High-wire Tomato as Affected by Supplemental Light Source and Distribution within the Canopy
}

\author{
Celina Gómez and Cary A. Mitchell ${ }^{1}$ \\ Department of Horticulture and Landscape Architecture, Purdue University, 625 Agriculture Mall \\ Drive, West Lafayette, IN 47907-2010
}

\begin{abstract}
Additional Index words. $\mathrm{CO}_{2}$ assimilation, leaf senescence, light-emitting diode, high-pressure sodium, Solanum lycopersicum, solid-state lighting

ABstract. The relative coolness-to-touch of light-emitting diodes (LEDs) has enabled commercial implementation of intracanopy lighting (ICL) in the greenhouse. Intracanopy lighting, which refers to the strategy of lighting along the side or from within the foliar canopy, can increase canopy photosynthetic activity, but physiological and productivity responses of high-wire greenhouse tomato (Solanum lycopersicum) to intracanopy supplemental lighting (SL) still are not yet fully understood. Two consecutive production experiments were conducted across seasons in a glass-glazed greenhouse located in a midnorthern, continental climate [lat. $40^{\circ} \mathrm{N}$ (West Lafayette, IN)]. Plants were grown from winter-to-summer [increasing solar daily light integral (DLI)] and from summer-to-winter (decreasing solar DLI) to compare three SL strategies for high-wire tomato production across changing solar DLIs: top lighting with highpressure sodium lamps (HPS) vs. intracanopy LED vertical towers vs. hybrid SL (HPS + horizontal ICL-LEDs). A control treatment also was included for which no SL was provided. Supplemental DLI for each experimental period was adjusted monthly, to complement seasonal changes in sunlight, aiming to approach a target total DLI of 25 $\mathrm{mol} \cdot \mathrm{m}^{-2} \cdot \mathrm{d}^{-1}$ during fruit set. Harvest parameters (total fruit fresh weight, number of fruit harvested, and average cluster fresh weight), tissue temperature, chlorophyll fluorescence, and stomatal conductance ( $\left.g_{S}\right)$ were unaffected by $\mathrm{SL}$ treatment in both experiments. Among the physiological parameters evaluated, $\mathrm{CO}_{2}$ assimilation measured under light-saturating conditions, light-limited quantum-use efficiency, and maximum gross $\mathrm{CO}_{2}$ assimilation $\left(A_{\text {max }}\right)$ proved to be good indicators of how ICL reduces the top-to-bottom decline in leaf photosynthetic activity otherwise measured with top lighting only (HPS-SL or solar). Although SL generally increased fruit yield relative to control, lack of SL treatment differences among harvest parameters indicates that higher crop photosynthetic activity did not increase fruit yield. Compared with control, intracanopy SL increased yield to the same extent as top SL, but the remaining photoassimilate from ICL most likely was partitioned to maintain nonharvested, vegetative plant parts as well.
\end{abstract}

Year-round production of greenhouse-grown tomatoes in temperate climates typically requires SL for optimal fruit yield and quality. High-pressure sodium lamps have been the lamp of choice for greenhouse SL because their high-intensity output delivers adequate photosynthetically active radiation $[P A R$ $(400-700 \mathrm{~nm})]$ to crops. Traditionally, HPS lamps are mounted overhead (i.e., delivering light from the top) at a fixed height that minimizes radiant heat load on crops but maximizes light distribution and uniformity at a given height within the greenhouse. Although the wide-angle beam distribution of top lighting can maximize upper-canopy photon capture efficiency for mature crops, when plants are young and widely spaced, energy is wasted when overhead-emitted photons fall on empty spaces within the production area (Nelson and Bugbee, 2014). For that reason, growers tend to adjust the DLI from HPS SL depending on plant development. Nonetheless, when foliar canopies close, photons coming from above are excluded from the inner canopy, and mutual shading occurs,

Received for publication 28 Oct. 2015. Accepted for publication 11 Jan. 2016. Research funded in part by the National Institute of Food and Agriculture, Specialty Crops Research Initiative grant 2010-51181-21369. Statistical assistance from Judy Santini with the Purdue College of Agriculture Statistical Consulting Service is gratefully acknowledged.

We thank Syndicate Sales for growth media, DeRuiter Seeds for seed supply, MGS Horticultural Inc. for biocontrol, and Philips Lighting for lamp donation. ${ }^{1}$ Corresponding author. E-mail: cmitchel@purdue.edu. leading to a vertical gradient decline in leaf photosynthesis (Frantz et al., 2000).

Unlike HPS lamps, the relative coolness of LEDs allows them to operate in close proximity to plant tissue, thereby increasing available $P A R$ at leaf level without causing thermal stress, while waste heat from the LEDs is dispersed elsewhere. What's more, providing SL directly inside the vertically dense foliar canopies of high-wire crops [e.g., tomato, cucumber (Cucumis sativus), sweet pepper (Capsicum annuum), and eggplant (Solanum melongena)] should overcome shading of middle and lower-canopy leaves by upper leaves, and potentially row-to-row shading as the sun tracks across the greenhouse. "Intracanopy lighting" or "interlighting," both of which refer to the strategy of lighting along the side or within the foliar canopy, prevent mutual shading for such high-wire crops. For this article, we use the terms "ICL" and "interlighting" interchangeably.

Intracanopy lighting in a sole-source-lighting mode delayed leaf senescence for cowpea [Vigna unguiculata (Frantz et al., 2000; Massa et al., 2005)] and soybean [Glycine max (Stasiak et al., 1998)] by maintaining irradiance above the lightcompensation point of the inner foliar canopy. Studies have shown that hybrid SL (top + ICL) increased crop photosynthesis in high-wire greenhouse production of tomatoes (Dueck et al., 2012), cucumbers (Pettersen et al., 2010; Trouwborst et al., 2010), and field-grown soybeans (Johnston et al., 1969) by maintaining positive photosynthetic activity of middle- and 
lower-canopy leaves. Moreover, hybrid SL increases light-use efficiency (yield per unit electric energy consumption for lighting) within high-wire greenhouse-grown crops by delivering uniform light distribution along vertical leaf profiles.

Most research evaluating intracanopy SL uses ICL as part of hybrid lighting (Dueck et al., 2012; Gunnlaugsson and Adalsteinsson, 2006; Hao et al., 2012; Heuvelink et al., 2006; Hovi et al., 2004; Hovi-Pekkanen et al., 2006; Hovi-Pekkanen and Tahvonen, 2008; Pettersen et al., 2010; Trouwborst et al., 2010). Other studies have used ICL alone (Deram et al., 2014; Gómez et al., 2013; Grimstad, 1987; Jokinen et al., 2012; Lu et al., 2012a, 2012b). Moreover, a direct comparison of physiological responses of leaves developed using HPS, ICLLED, or hybrid SL has not been reported for high-wire tomato. Our objectives were to 1) compare physiological responses to different SL sources and positions within an indeterminate high-wire tomato canopy in a winter-to-summer and a summerto-winter production cycle; and to 2) quantify productivity and energy consumption for crops grown under the different lighting treatments. We hypothesized that 1) ICL would maintain higher photosynthetic capacity for middle and lower leaves within a high-wire tomato canopy compared with top lighting (solar or HPS-SL); and that 2) due to the expected increase in crop photosynthesis, tomatoes grown with ICL would achieve higher fruit yield compared with that of plants grown with HPS or no SL, respectively, while reducing electrical energy consumption from SL compared with HPS. Gas exchange, tissue temperature, and chlorophyll fluorescence measurements were included to help elucidate anticipated physiological responses to intracanopy SL for greenhouse tomato production during opposite seasonal-transition experiments. Additionally, fruit-yield and energy-consumption measurements would further reveal potential production benefits from using intracanopy SL.

\section{Materials and Methods}

\section{Winter-to-summer}

Plant material ANd growing Conditions. Seeds of tomato 'Komeett' (De Ruiter Seeds, Bergschenhoek, The Netherlands) were sown into 17-cell seedling trays of Agrifoam soil-less plugs $[5 \times 2.5 \mathrm{~cm}$ (SteadyGROWpro; Syndicate Sales, Kokomo, IN)] on 16 Dec. 2013 and placed in a glass-glazed greenhouse in West Lafayette, IN (lat. $40^{\circ} \mathrm{N}$, long. $86^{\circ} \mathrm{W}$ ). The greenhouse is oriented east-to-west with $3.7 \mathrm{~m}$ gutter height, $6.7 \mathrm{~m}$ peak height, and a floor area of $111 \mathrm{~m}^{2}$. Once the cotyledons had expanded fully, SL of $100 \pm 3.2 \mu \mathrm{mol} \cdot \mathrm{m}^{-2} \cdot \mathrm{s}^{-1}$ from an HPS lamp (Ceramalux; Philips Lighting Co., Somerset, NJ) was provided for $14 \mathrm{~h}$ daily. All seedlings were fertigated as necessary with acidified water supplemented with a combination of two water-soluble fertilizers (a $3: 1$ mixture of $15 \mathrm{~N}-$ $2.2 \mathrm{P}-12.5 \mathrm{~K}$ and $21 \mathrm{~N}-2.2 \mathrm{P}-16.6 \mathrm{~K}$, respectively; The Scotts Co., Marysville, $\mathrm{OH}$ ) to provide the following (in $\mathrm{mg} \cdot \mathrm{L}^{-1}$ ): $200 \mathrm{~N}$, $26 \mathrm{P}, 163 \mathrm{~K}, 50 \mathrm{Ca}, 20 \mathrm{Mg}$, and micronutrients. On 9 Jan. 2014, uniform seedlings were selected to receive the lighting treatments and were subsequently transplanted into Agrifoam rooting blocks $(4 \times 4 \times 2.5 \mathrm{~cm}$, SteadyGROWpro $)$, which were then placed on top of wetted coconut coir slabs $[50 \times 15 \times 10 \mathrm{~cm}$ (Riococo 200; Ceyhinz Link International, Dallas/Fort Worth Metroplex of Texas, TX)]. Slabs were placed on top of custommade steel gutters $[10 \mathrm{~m} \times 25 \mathrm{~cm}$ (FormFlex Horticultural Systems, Beamsville, ON, Canada)]. The stem density was
2.3 stems $/ \mathrm{m}^{2}$. Plants were fertigated with a commercial complete fertilizer mix [4.5N-14P-34K (CropKing, Lodi, OH)] and duration and frequency adjusted to provide a daily leaching fraction of $30 \%$. Electrical conductivity (EC) and $\mathrm{pH}$ of the influx and efflux fluids were measured daily with a hand-held EC and pH meter (9813-6; Hanna Instruments, Woonsocket, $\mathrm{RI})$ to ensure that values were maintained within recommended ranges $\left(2.5\right.$ to $3.5 \mathrm{dS} \cdot \mathrm{m}^{-1}$ and 5.8 to 6.3 for $\mathrm{EC}$ and $\mathrm{pH}$, respectively) (Jones, 2008). Ambient day (from 0500 to 2100 $\mathrm{HR}$ ) and night (from 2100 to $0500 \mathrm{HR}$ ) temperatures of the greenhouse were set at 25 and $15^{\circ} \mathrm{C}$, respectively. Depending on ambient temperature, the greenhouse was cooled as needed using a pad-and-fan evaporative-cooling system or heated using radiant hot-water-pipe heating regulated by an environmental control system (Maximizer Precision 10; Priva Computers, Vineland Station, ON, Canada).

Lighting TREATMEnts. The greenhouse floor area was divided into three rows ( $2.4 \mathrm{~m}$ from center-to-center) separated by movable double layers of $0.15-\mathrm{mm}$-thick white polyethylene curtains. The plastic curtains hung parallel to the rows from the upper frame of the greenhouse structure $(\approx 4.7 \mathrm{~m}$ from the top to the floor) and were used to prevent light pollution between treatments; curtains were withdrawn when lamps were off. Each row was divided into four 2.5-m-long sections of different treatments running in an east-to-west direction separated by short sections of plastic curtains $(1.2 \times 4.5 \mathrm{~m})$ hanging perpendicular within each row to separate treatments within a row. Each section was one replicate of a treatment lighting eight single-headed plants (two side-by-side plants per slab, four slabs per section) that were leaned and lowered within each treatment replication.

The SL treatments were started on 31 Jan. 2014 and adjusted monthly to complement seasonal changes in solar DLI (Korczynski et al., 2002; assuming 50\% solar light transmission into the greenhouse) aiming for a total target DLI of $25 \mathrm{~mol} \cdot \mathrm{m}^{-2} \cdot \mathrm{d}^{-1}$ during fruit set. Three SL treatments were evaluated: 1) two top $600-W$ HPS lamps [power consumption (at 208V as indicated by the manufacturer $)=639 \mathrm{~W}$ (HS2000; P.L. Lights, Beamsville, ON, Canada)] emitting $4 \%, 47 \%$, and $49 \%$ broadband blue (400 to $500 \mathrm{~nm}$ ), green (500 to $600 \mathrm{~nm})$, and red (600 to $700 \mathrm{~nm}$ ) light, respectively; 2) two actively air-cooled LED vertical towers (ICL-LED) [2.5 m tall, power consumption at full power $=1240 \mathrm{~W}$ (Orbital Technologies Corp., Madison, WI)] with three separately controlled LED zones $(0.60 \times 0.12 \mathrm{~m})$ irradiating in both directions within a row. Each tower had two opposite panels within each zone, each of which had four red and one blue (627 and 450-nm peak wavelength, respectively) dimmable lighting strips with 12 LEDs mounted vertically within each strip; or 3) hybrid lighting using a two-tiered, passively air-cooled, horizontal LED interlighting module [2.5 m long, $60 \mathrm{~cm}$ between interlights, power consumption $=129 \mathrm{~W}$ per interlight (GreenPower LED interlighting $\mathrm{dr} / \mathrm{b}$; Philips, Eindhoven, The Netherlands)] placed $\approx 60 \mathrm{~cm}$ below the top of the plant + two top 350-W HPS lamps [power consumption $=406 \mathrm{~W}(\mathrm{LU} 400 \mathrm{ECO}$; Sylvania, Toronto, ON, Canada)] emitting 6\%, 31\%, and 63\% broadband blue, green, and red light (BGR), respectively. Each interlight had a two opposite horizontal strips with 160 red and 40 blue LEDs (four red for every blue LED; 660 and 450-nm peak wavelengths, respectively) radiating horizontally in both directions within a row of eight side-by-side plants. Both LED lamp types provided a mix of $93 \%$ red and $7 \%$ blue. A control treatment also was included for which no SL was provided. 
Before starting each experiment, a light map was developed (after sunset) at three heights in the greenhouse to determine the maximum photosynthetic photon flux $(P P F)$ for each SL treatment (no plants present). The measured heights corresponded to the center of each vertical panel in an LED tower. Light intensity was measured using a spherical quantum sensor (LI-250A; LI-COR Biosciences, Lincoln, NE) calibrated for each treatment against a spectroradiometer (EPP-2000; StellarNet, Tampa, FL). Table 1 shows the different parameters used for SL; the output of supplemental DLI (photons emitted per fixture) was set to be equivalent for all treatments. However, each treatment had a different distribution of PPF along the vertical profile of the crop stand. In addition, the total average $P P F$ from hybrid SL was higher than that of the two other SL treatments and, thus, a slightly different photoperiod was used to achieve the same supplemental DLI. Supplemental lighting provided an average DLI (at plant height) of 9.7, 12.5, 9.0, 3.8, and $3.8 \mathrm{~mol} \cdot \mathrm{m}^{-2} \cdot \mathrm{d}^{-1}$ for February, March, April, May, and June, respectively. The photoperiod, number of energized zones within a tower, and interlights within a hybrid treatment depended on plant growth and monthly SL-DLI requirements.

Solar DLI and air temperature in the greenhouse were monitored using quantum sensors (LI190SB, LI-COR Biosciences) and shielded temperature probes (107-L; Campbell Scientific, Logan, UT), respectively, interfaced to a data logger (CR1000, Campbell Scientific). Solar DLI was monitored at three heights within the greenhouse: 1) midcanopy height in control treatments, 2) directly above top-canopy height in control treatments, and 3) top of the greenhouse rafters (two sensors placed in different locations). Shielded temperature probes were placed at midcanopy height in the center of each treatment replication (a total of 12 sensors). Measurements were made every $10 \mathrm{~s}$ and average data were recorded at 10-min intervals. Average solar DLI and typical day and night air temperature measured during the experimental period are reported in Fig. 1.
Data collection. Megajoules of energy consumed were monitored using a built-in data logger or energy monitors (e2 classic 2.0; Efergy USA, Miami, FL) for each ICL-LED tower or HPS and hybrid lighting treatments, respectively. Removal of lower leaves and plant leaning and lowering were conducted as needed. Fruit were pruned to five per cluster (to maintain fruit grade/size uniformity), and clusters were harvested weekly when the last fruit within a cluster was at maturation stage 6, based on U.S. Department of Agriculture Visual Aid TM-L-1 tomato-color standards (U.S. Department of Agriculture, 1975). Fruit fresh weight and fruit number were recorded immediately following harvest.

The maximum photosystem II efficiency $\left(F_{\mathrm{v}} / F_{\mathrm{m}}\right)$ was estimated by measuring chlorophyll fluorescence using a portable pulse-modulated chlorophyll fluorometer (OS-30p; OptiSciences, Hudson, NH) to determine whether onset of leaf senescence was associated with plant responses to changing light conditions in the growth environment (i.e., self or mutual shading). An inner-canopy and an outer-canopy (adjacent to the aisle) leaf was selected for four plants per treatment replication. Leaves to be measured were tagged with colored plastic bands wrapped around the base of the petiole of the newest leaf $\geq 16$ $\mathrm{cm}$ long $\left(\mathrm{L}_{1}\right)$, which corresponded to the upper canopy. Data were collected for the adaxial epidermis of the largest leaflet (typically the middle leaflet) within a leaf. Measurements were collected on target leaves to reduce leaf-to-leaf variability throughout canopy development (from leaf initiation to pruning). Fluorescence measurements were collected at weekly intervals for 6 weeks starting $21 \mathrm{Apr}$. Data were recorded at night ( $>30$ min after SL switched off) to ensure dark adaptation. Tissue temperature was recorded with a hand-held IR thermometer (Agry-Therm II; Everest Interscience, Tucson, AZ) (emissivity $=0.97)$; measurements were recorded on three random dates (forecasted for clear skies) between 0800 and $1100 \mathrm{HR}$ (while SL was in use). Temperature data were recorded for the apical meristem (shoot tip), newest fully expanded leaf (eighth leaf below $\left.\mathrm{L}_{1}\right)$, and oldest leaf $\left(\approx 18\right.$ th leaf below $\left.\mathrm{L}_{1}\right)$.

Table 1. Lighting parameters for each of three supplemental lighting (SL) treatments [600 W top high-pressure sodium lamps (HPS) versus intracanopy light-emitting diode (ICL-LED) vertical towers versus hybrid lighting ( $350 \mathrm{~W}$ top HPS lamps + horizontal ICL-LEDs)] used for the production of high-wire greenhouse tomatoes during opposite seasonal transition experiments in 2014. Data for photosynthetic photon flux $(P P F)$ represent light delivered at the top $(\mathrm{T})$, middle $(\mathrm{M})$, and bottom $(\mathrm{B})$ of the canopy as well as the average (Avg) $P P F$ across heights. Daily light integral (DLI) was calculated based on the average $P P F^{\mathrm{z}}$.

\begin{tabular}{|c|c|c|c|c|c|c|c|c|c|c|c|c|c|c|c|c|c|c|c|c|}
\hline \multirow[b]{3}{*}{ Season } & \multicolumn{15}{|c|}{$P P F\left(\mu \mathrm{mol} \cdot \mathrm{m}^{-2} \cdot \mathrm{s}^{-1}\right)$} & \multirow{2}{*}{\multicolumn{4}{|c|}{ Photoperiod (h) }} & \multirow{3}{*}{$\begin{array}{c}\text { DLI } \\
\left(\mathrm{mol} \cdot \mathrm{m}^{-2} \cdot \mathrm{d}^{-1}\right)\end{array}$} \\
\hline & & \multicolumn{3}{|c|}{ HPS } & & & & & \multicolumn{7}{|c|}{ Hybrid } & & & & & \\
\hline & $\mathrm{T}$ & $\mathrm{M}$ & $\mathrm{B}$ & $\overline{\mathrm{Avg}}$ & $\mathrm{T}$ & $\mathrm{M}$ & $\mathrm{B}$ & Avg & $\mathrm{T}$ & $\mathrm{M} \mathrm{B}$ & Avg & $\mathrm{T}$ & $\mathrm{M}$ & $\mathrm{B}$ & $\mathrm{Avg}$ & HPS & ICL-LED & \multicolumn{2}{|c|}{$\overline{\text { HPS ICL-LED }}$} & \\
\hline February & - & 180 & 118 & 149 & - & 149 & 149 & 149 & - & -- & - & - & 154 & - & 154 & 18.0 & 18.0 & 0.0 & 17.5 & 9.7 \\
\hline March & 282 & 180 & 118 & 193 & 193 & 193 & 193 & 193 & 71 & 3424 & 43 & - & 154 & - & 154 & 18.0 & 18.0 & 17.6 & 17.6 & 12.5 \\
\hline April & 282 & 180 & 118 & 193 & 193 & 193 & 193 & 193 & 71 & 3424 & 43 & - & 154 & - & 154 & 13.0 & 13.0 & 13.0 & 12.7 & 9.0 \\
\hline June & 282 & 180 & 118 & 193 & 193 & 193 & - & 193 & 71 & 3424 & 43 & - & 154 & - & 154 & 5.5 & 5.5 & 5.4 & 5.4 & 3.8 \\
\hline \multicolumn{21}{|c|}{ Summer-to-winter } \\
\hline September & 274 & 150 & 95 & 173 & 173 & 173 & 173 & 173 & 66 & 3122 & 40 & - & 140 & - & 140 & 16.0 & 16.0 & 15.4 & 15.4 & 10.0 \\
\hline October & 274 & 150 & 95 & 173 & 173 & 173 & 173 & 173 & 66 & 3122 & 40 & - & 140 & - & 140 & 18.0 & 18.0 & 17.3 & 17.3 & 11.2 \\
\hline November & 274 & 150 & 95 & 173 & 173 & 173 & 173 & 173 & 66 & 3122 & 40 & - & 140 & - & 140 & 18.0 & 18.0 & 17.3 & 17.3 & 11.2 \\
\hline December & 274 & 150 & 95 & 173 & 173 & 173 & - & 173 & 66 & 3122 & 40 & - & 140 & - & 140 & 18.0 & 18.0 & 17.3 & 17.3 & 11.2 \\
\hline
\end{tabular}

${ }^{\mathrm{z}} P P F$ data were collected before transplanting; the measured heights for $P P F$ corresponded to the center of each vertical panel in an ICL-LED tower. For both ICL-LED and hybrid SL, data were collected $15 \mathrm{~cm}$ away from each panel/interlight and measured using a spherical quantum sensor calibrated against a spectroradiometer. 


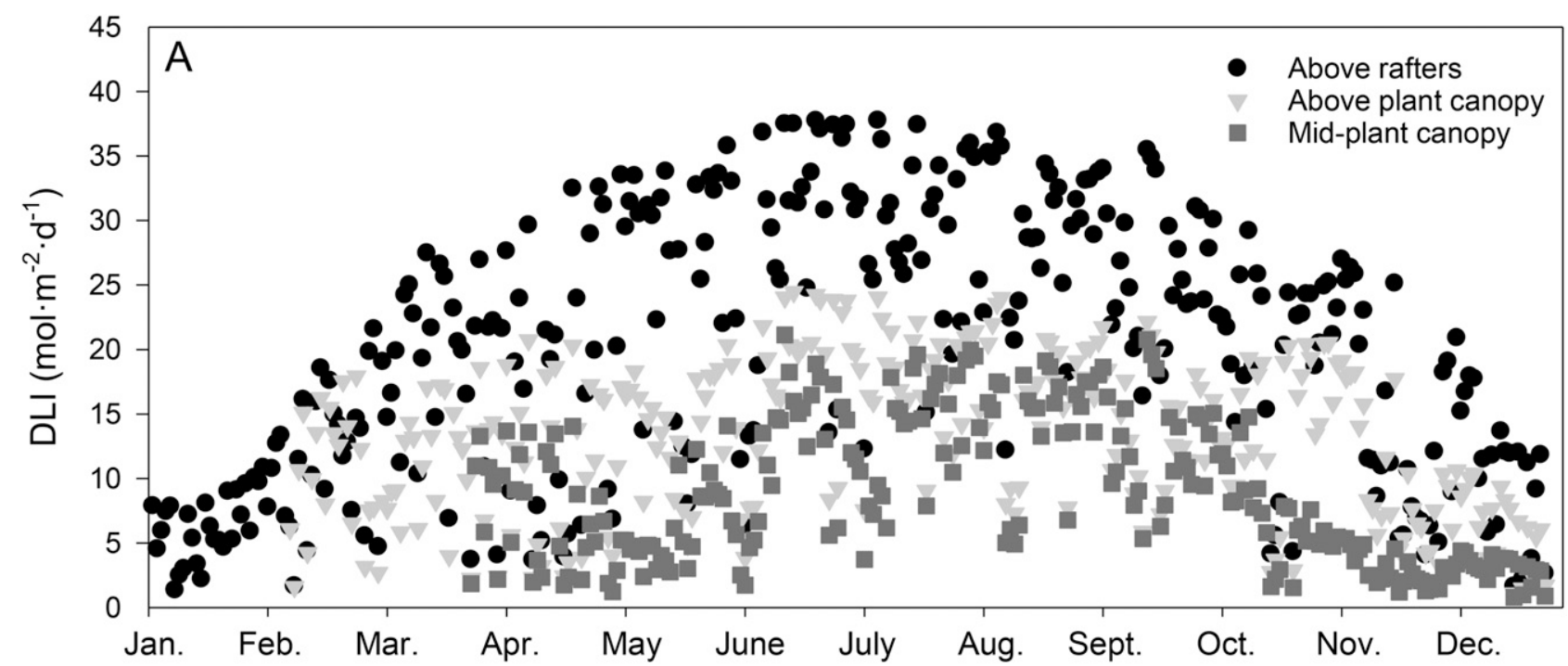

Month
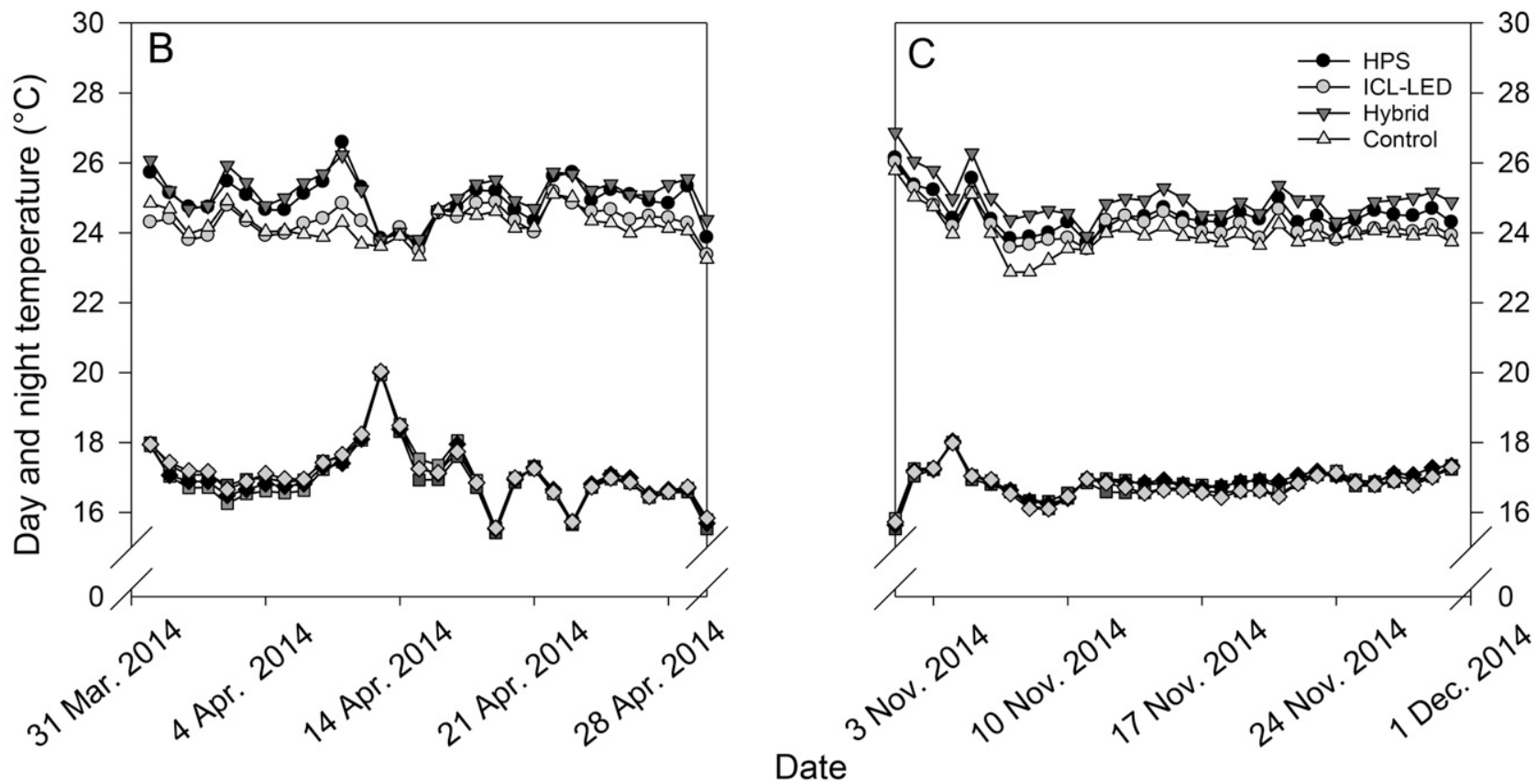

Fig. 1. Solar daily light integral (DLI) in (A) 2014 and typical ambient day and night (upper and lower lines, respectively) greenhouse-air temperatures measured inside a glass-glazed greenhouse during, $(\mathbf{B})$ a winter-to-summer or $(\mathbf{C})$ a summer-to-winter experiment. Temperature data were recorded under one of four lighting treatments: solar + supplemental lighting from top-high-pressure sodium lamps (HPS), intracanopy light-emitting diode (ICL-LED) vertical towers, hybrid lighting (top-HPS + horizontal ICL-LEDs), or unsupplemented controls.

Gas-exchange measurements were performed using a portable leaf-gas-exchange- measurement system (CIRAS-3; PP Systems, Amesbury, MA) fitted to a $4.5 \mathrm{~cm}^{2}$ leaf chamber with built-in LEDs $(475,528,625$, and 425 to $650-\mathrm{nm}$ peak wavelengths for the blue, green, red, and white LEDs, respectively). All gas-exchange measurements were conducted on three leaf layers: newest fully expanded leaf [LL1 $(\approx$ eighth leaf below $\left.\mathrm{L}_{1}\right)$ ], 13th leaf below $\mathrm{L}_{1}$ (LL2), and the oldest leaf [LL3 $\left(\approx 18\right.$ th leaf below $\left.\mathrm{L}_{1}\right)$ ]. For each leaf layer, six leaves from different plants within a treatment were randomly selected for measurement; data were collected from the largest leaflet of a given leaf. All measurements were conducted between 0900 and $1400 \mathrm{HR}$ (while SL was in use). Assimilation of $\mathrm{CO}_{2}(A)$ and $g_{\mathrm{s}}$ were measured using $P P F \mathrm{~s}$ of 1000 and $200 \mu \mathrm{mol} \cdot \mathrm{m}^{-2} \cdot \mathrm{s}^{-1}$ to determine light-saturated $\left(L_{\mathrm{sat}}\right)$ and light-limited $\left(L_{\mathrm{lim}}\right)$ rates of gas exchange under predefined environmental conditions (as opposed to survey measurements under ambient conditions). Two weeks before collecting $L_{\mathrm{sat}}$ and $L_{\mathrm{lim}}$ measurements, spectral scans for each treatment (SL + sunlight) were collected at each leaf layer on three clear-sky days (at solar noon). Spectral percentages for broadband BGR were calculated and averaged across leaf layers for each lighting treatment. The light unit in the cuvette was programed to correspond to a treatment-specific spectrum: HPS $=24 \%, 39 \%$, and $37 \%$ BGR, respectively; ICL-LED $=28 \%, 24 \%$, and $48 \%$ BGR, respectively; hybrid $=31 \%, 32 \%$, and $37 \%$ BGR, respectively; 
and solar $($ control $)=33 \%, 34 \%$, and 33\% BGR, respectively. To reveal differences when measuring gas exchange under a treatment-specific vs. a common spectrum across samples, $L_{\text {sat }}$ and $L_{\text {lim }}$ measurements were conducted first, using a treatmentspecific spectrum followed by measurements under the predetermined solar spectrum BGR ratio. The reference $\mathrm{CO}_{2}$ concentration, leaf temperature, relative humidity, and flow rate through the chamber were $400 \mu \mathrm{mol} \cdot \mathrm{mol}^{-1}, 25^{\circ} \mathrm{C}, \approx 60 \%$, and $300 \mathrm{~mL} \cdot \mathrm{min}^{-1}$, respectively.

Survey $A$ and $g_{\text {s }}$ were measured on overcast and clear-sky days to compare physiological responses under contrasting solar light intensities. Data were collected under ambient light, temperature, and relative humidity; reference $\mathrm{CO}_{2}$ concentration and flow rate through the cuvette chamber were 400 $\mu \mathrm{mol} \cdot \mathrm{mol}^{-1}$ and $300 \mathrm{~mL} \cdot \mathrm{min}^{-1}$, respectively. Measurements were conducted from 15 to 17 (overcast) and 19 to $22 \mathrm{Apr}$. (clear sky); during this period, average solar DLI directly above plant canopy was 6.5 and $17.8 \mathrm{~mol} \cdot \mathrm{m}^{-2} \cdot \mathrm{d}^{-1}$ for overcast and clear-sky days, respectively.

Photosynthetic light-response curves were characterized at seven different PPF levels (1000, 800, 500, 350, 200, 75, and $\left.0 \mu \mathrm{mol} \cdot \mathrm{m}^{-2} \cdot \mathrm{s}^{-1}\right)$. The light unit in the cuvette was programed to provide $33 \%, 34 \%$, and $33 \%$ BGR. The reference $\mathrm{CO}_{2}$ concentration, leaf temperature, relative humidity, and flow rate inside the chamber were $400 \pm 5 \mu \mathrm{mol} \cdot \mathrm{mol}^{-1}, 26^{\circ} \mathrm{C}, 60 \%$, and $300 \mathrm{~mL} \cdot \mathrm{min}^{-1}$, respectively. Data were fitted to the following model equation:

$$
\begin{aligned}
A_{\text {net }}= & -R_{\mathrm{d}}+\left\{\theta \times P P F+A_{\max }\right. \\
& \left.-\sqrt{ }\left[\left(\theta \times P P F+A_{\max }\right)^{2}-4 \theta \times P P F \times k \times A_{\max }\right]\right\} / 2 k
\end{aligned}
$$

where $A_{\text {net }}$ is net $\mathrm{CO}_{2}$ assimilation rate, $R_{\mathrm{d}}$ is dark respiration, $\theta$ is quantum-use efficiency, $P P F$ is the incident irradiance, $A_{\max }$ is maximum gross $\mathrm{CO}_{2}$ assimilation (light-saturated net $\mathrm{CO}_{2}$ assimilation $+R_{\mathrm{d}}$ ), and $k$ is the curvature factor describing the convexity of the curve. Light-compensation point was calculated as the $P P F$-associated photosynthetic rates when $A_{\text {net }}=0$. Data for light-response curves were collected from 26 to 31 May and the experiment was ended on 16 June 2014. conducted from 21 to 22 (clear sky) and 24 to 25 Nov. (overcast); during this period, average solar DLI directly above plant canopy was 2.7 and $12.8 \mathrm{~mol} \cdot \mathrm{m}^{-2} \cdot \mathrm{d}^{-1}$ for overcast and clear-sky days, respectively. Data for light-response curves were collected from 17 to 22 Nov. and the experiment was ended on 13 Dec. 2014.

EXPERIMENTAL DESIGN AND STATISTICAL aNALYSIS. Because error variance was not homogeneous between experiments, statistical analyses were conducted separately for each production cycle. Harvest parameters and tissue temperature were analyzed according to a randomized complete block (RCB) design. Fluorescence data were analyzed as an RCB design with 6 weeks $\times$ two canopy sides $\times$ four lighting treatments as factorial levels. Gas-exchange data (except for light-response curves) were analyzed as an RCB design with three leaf layers $\times$ four lighting treatments as factorial levels. A nonrectangular hyperbola was used to fit light-response curve data using the nonlinear fitting procedure of SAS (version 9.2; SAS Institute, Cary, NC). Analysis of variance and mean separation by Tukey's honestly significant difference test $(P \leq 0.05)$ were performed for all data using SAS. Data were pooled when interactions between or among factors were not significant $(P \leq$ $0.05)$ and are presented as main effects only.

\section{Results and Discussion}

Fruit yield. No treatment differences were found among SL treatments for any harvest parameter evaluated in either experiment (Table 2). During winter-to-summer, SL increased yield by at least 33\% compared with unsupplemented controls. Although plants grown with ICL-LED produced clusters similar in fresh weight to those of plants grown without SL, $23 \%$ more fruit were produced using ICL-LED SL, most likely due to the higher flower abortion observed for controls. Fruit clusters of plants grown under HPS or hybrid SL were $27 \%$ or $29 \%$ larger than those of controls, respectively. Although the increase in fruit number from SL ranged from $16 \%$ up to $23 \%$, the number of fruit produced per plant under hybrid SL was not statistically different from that of plants grown without SL (108 vs. 93 fruit). During summer-to-winter, SL increased fruit yield up to $108 \%$ relative to that of control due to a combination of more and larger fruit.

\section{Summer-to-winter}

Seeds of 'Komeett' were sown on 20 June 2014. Plants were grown under conditions identical to the winter-to-summer experiment and data recorded were the same with the following exceptions: 1) due to high solar DLI and ambient temperature at the beginning of the experiment, SL treatments were initiated on 1 Sept. 2014 and, thus, used only during the last $\approx 3.5$ months of production; 2) average DLI values (at plant height) from SL were 10.0, 11.2, 11.2 , and $11.2 \mathrm{~mol} \cdot \mathrm{m}^{-2} \cdot \mathrm{d}^{-1}$ for September, October, November, and December, respectively (Table 1); 3) $L_{\text {sat }}$ and $L_{\text {lim }}$ measurements were conducted using 33\%, 34\%, and 33\% BGR; 4) survey measurements were
Table 2. Harvest parameters for two side-by-side tomato plants grown in a greenhouse under one of four lighting treatments [solar + supplemental lighting from top-high-pressure sodium lamps (HPS), intracanopy light-emitting diode (ICL-LED) vertical towers, hybrid lighting (top-HPS + horizontal ICL-LEDs), or unsupplemented controls] during opposite seasonal transition experiments in 2014.

\begin{tabular}{lccc}
\hline Treatments & Total fruit FW $(\mathrm{g})$ & Fruit harvested (no.) & Avg cluster FW (g) \\
\hline Winter-to-summer & $15,521 \mathrm{a}^{\mathrm{z}}$ & $114 \mathrm{a}$ & $622 \mathrm{a}$ \\
HPS & $14,268 \mathrm{a}$ & $114 \mathrm{a}$ & $570 \mathrm{ab}$ \\
ICL-LED & $14,864 \mathrm{a}$ & $108 \mathrm{ab}$ & $633 \mathrm{a}$ \\
Hybrid & $10,753 \mathrm{~b}$ & $93 \mathrm{~b}$ & $490 \mathrm{~b}$ \\
Control & & & $520 \mathrm{a}$ \\
Summer-to-winter & $15,926 \mathrm{a}$ & $143 \mathrm{a}$ & $539 \mathrm{a}$ \\
HPS & $16,781 \mathrm{a}$ & $148 \mathrm{a}$ & $530 \mathrm{a}$ \\
ICL-LED & $16,871 \mathrm{a}$ & $158 \mathrm{a}$ & $355 \mathrm{~b}$ \\
Hybrid & $8,116 \mathrm{~b}$ & $95 \mathrm{~b}$ & \\
Control & & & \\
\hline
\end{tabular}

${ }^{\mathrm{z}}$ Mean within production cycle and within columns followed by the same letter are not different based on the least significant difference test $(P \leq 0.05)$.

$\mathrm{FW}=$ fresh weight. 
Results from this study indicate that SL generally increases fruit yield (size, weight, and/or number) under solar lightlimited conditions, compared with unsupplemented controls, regardless of production season, SL source, or SL position within the canopy (Table 2). Furthermore, because 'Komeett' is a source-limited variety, larger fruit in response to SL were expected (Gómez and Mitchell, 2014). It is well established that SL is needed to maintain or increase fruit production in lightlimited environments, especially for high-light-requiring crops such as tomato (Blacquiere and Spaargaren, 2003; GajcWolska et al., 2013). Moreover, if no other factors are limiting, productive crop yield can be achieved by providing adequate $P P F$ or optimal DLI. In our study, supplemental DLI was kept constant across treatments and, thus, may account for the similarities in fruit production among SL treatments.

Although hybrid lighting has been shown to improve lightuse efficiency, to increase fruit yield and percentage of firstclass fruit, and to extend the postharvest shelf life of produce compared with those of top SL, most studies reporting increases in crop yield due to hybrid SL have used HPS lamps mounted above as well as within the canopy (as with ICL) (Gunnlaugsson and Adalsteinsson, 2006; Hovi et al., 2004; Hovi-Pekkanen et al., 2006; Hovi-Pekkanen and Tahvonen, 2008; Pettersen et al., 2010). In contrast, studies comparing hybrid SL using top-HPS lamps + ICL-fluorescent or -LED lamps to top-HPS lighting alone have shown either negative (Heuvelink et al., 2006), minimal (Hao et al., 2012), or no significant effects (Deram et al., 2014; Dueck et al., 2012; Trouwborst et al., 2010) on fruit yield. It is likely that increases in fruit yield when using top-HPS + ICL-HPS hybrid lighting are, in part, the result of the additional thermal energy irradiated into the canopy by ICLHPS, which could accelerate fruit-growth and/or maturation rates, affect partitioning of photoassimilate to fruit, and reduce time to harvest (Adams et al., 2001; Hurd and Graves, 1984; Pearce et al., 1993). Conversely, if ICL does not irradiate much heat, as in the case of the LED lamps used in our study, hybrid lighting may not increase yield of greenhouse-grown crops relative to other forms of SL.

ENERGY CONSUMPTION. Daily electrical energy consumption is shown in Fig. 2. During both experiments, average energy consumption was significantly different across treatments. From winter-to-summer, HPS, hybrid, and ICL-LED SL consumed an average of $118.8,79.2$, and $46.8 \mathrm{MJ} \cdot \mathrm{d}^{-1}$, respectively. Similarly, energy consumption during summer-towinter averaged $248.4,172.8$, and $97.2 \mathrm{MJ} \cdot \mathrm{d}^{-1}$ for HPS, hybrid, and ICL-LED SL, respectively. Regardless of season, at least $62 \%$ of the energy consumed by hybrid SL was due to the HPS component; the remaining $38 \%$ of energy was consumed by the LED interlights (data not shown).

A portion of the energy recorded for the HPS and hybrid treatments corresponds to light falling outside the growing area (aisles); those photons are included in the energy consumed by the HPS lamps but did not contribute to plant growth and development. In contrast, most of the photons delivered by ICL were targeted directly to photosynthetic tissue. Because of the different lamp architectures and lighting strategies used in these experiments, energy-use efficiency comparisons were not included in the study. A careful analysis for interpreting energy consumption from different SL technologies should take into account the lamp density required to achieve desired light intensities for optimal greenhouse production. It should also consider ideal fixture spacing needed to achieve uniform light

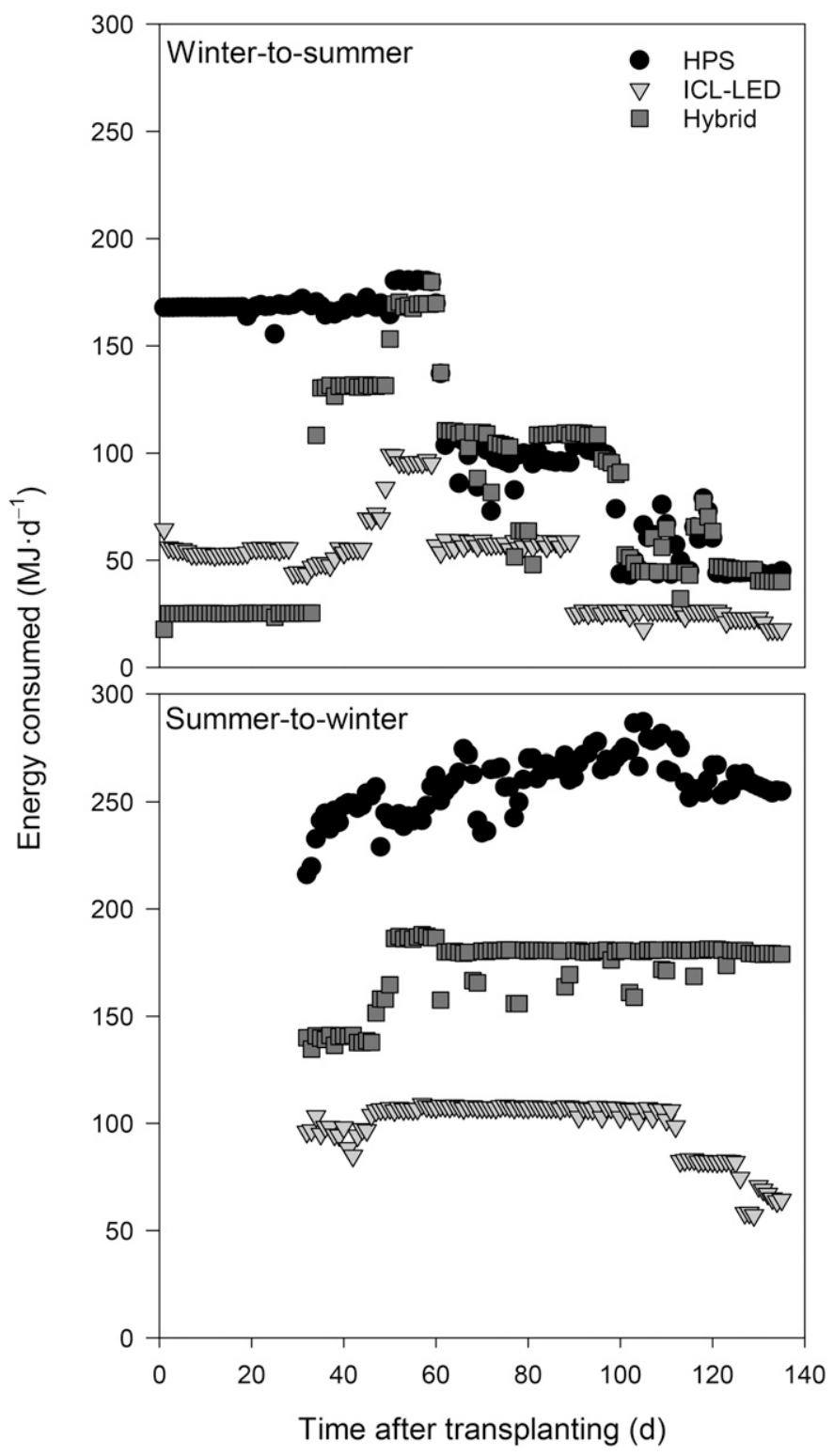

Fig. 2. Daily electrical energy consumption by three supplemental lighting treatments [600-W top-high-pressure sodium (HPS) lamps, intracanopy lightemitting diode (ICL-LED) vertical towers, or hybrid lighting (350-W top-HPS lamps + horizontal LED interlights)] used for the same production area of greenhouse-grown tomatoes during opposite seasonal transition experiments in 2014. Values represent the total energy consumed from three replications $\times$ two HPS lamps, ICL-LED towers, or HPS lamps + interlights.

distribution within the production area while reflecting some inherent differences between the systems (i.e., research-grade prototypes designed for "proof of concept" studies vs. energyefficient and cost-effective commercial prototypes) (Hernández and Kubota, 2015).

Electric savings from LED SL technologies are expected to increase in the near future, with ongoing improvements in power supplies and luminous efficacies in conjunction with decreasing operating costs of LEDs. Furthermore, a potential reduction in energy consumption from using ICL with LEDs also may be achieved by capability to focus radiation, which allows for additional electrical energy savings when selectively switching lights on/off, depending on the presence and location 
of photosynthetic leaf tissue. Figure 2 shows that during summer-towinter, megajoules per day for the ICL-LED treatment declined with approach to experiment termination, even though solar DLI was low. This occurred because bottom panels of the ICL-LED towers were switched off as plants were defoliated and fruit clusters were harvested from the bottom up, thereby saving additional energy by not lighting empty spaces. Although HPS SL allows for upper-canopy photon-capture efficiency to be maximized when mature crops are grown in large greenhouses with narrow aisles, focused SL with ICL can increase photon capture rates of canopies to near $100 \%$ (Nelson and Bugbee, 2014). However, focused radiation also makes it challenging for ICL to create uniform light distribution in large, open areas. In greenhouses, SL selection should primarily be based on the cost to deliver photons to the plant canopy and on potential competitive advantages from increasing productivity or affecting plant growth and/ or morphology.

Tissue Temperature. Measurements of tissue temperature served as a baseline to determine physiological differences possibly caused by the SL treatments. In general, and for a given plant part, tissue temperature was not significantly affected by SL treatment regardless of season (Fig. 3). Nelson and Bugbee (2015) concluded that environmental factors like water availability, leaf evaporative cooling, and light intensity can have a larger impact in determining leaf tissue temperature than radiation source per se. Except for light source and distribution, our plants were grown at equal environmental set points. Therefore, our findings suggest that yield and physiological responses could not be attributed to tissue temperature differences resulting from SL treatments. However, temperature of plant tissue at different heights within the selfshading high-wire profile of the crop did correspond with distance from the solar-lighted shoot tip to the mutually shaded lower canopy (Fig. 3). Others have shown that with top sole-source lighting, air,

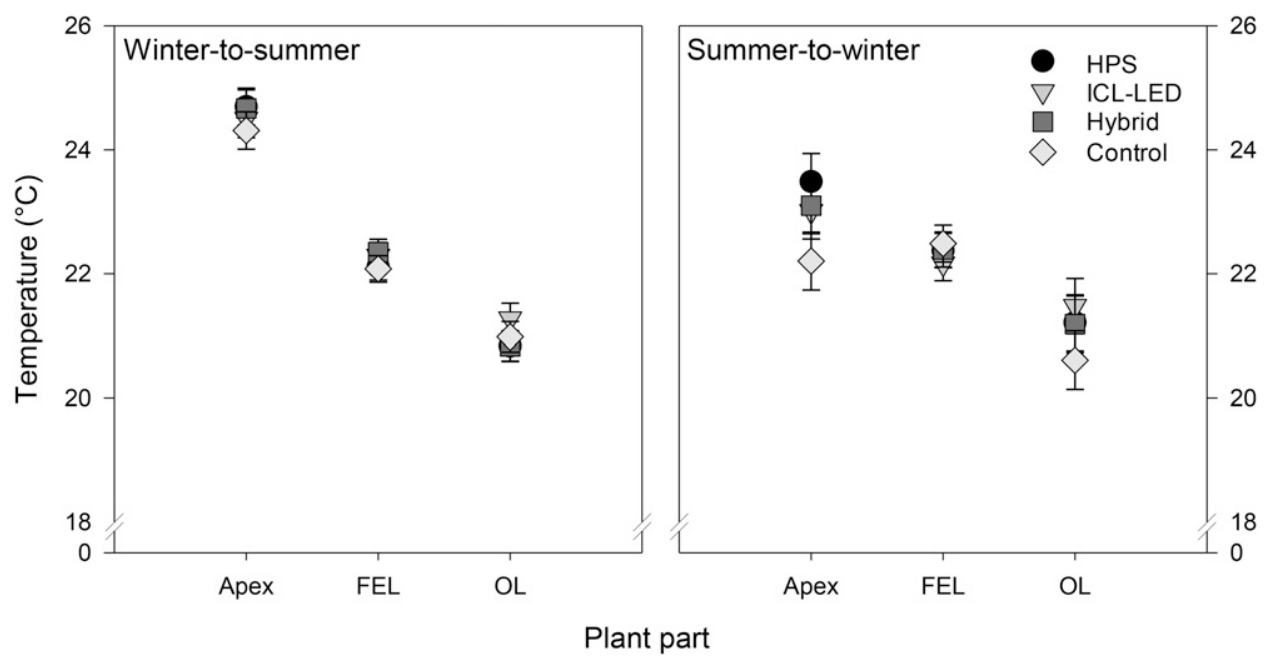

Fig. 3. Surface tissue temperature of tomato plants grown in a greenhouse under one of four lighting treatments during opposite seasonal transition experiments in 2014. The treatments evaluated were unsupplemented controls or solar + supplemental lighting from top-high-pressure sodium (HPS) lamps, intracanopy lightemitting diode (ICL-LED) vertical towers, or hybrid lighting (top-HPS + horizontal ICL-LEDs). Data were recorded for the shoot tip (apex), newest fully expanded leaf [FEL; eighth leaf below newest leaf $\geq 16 \mathrm{~cm}$ (L1)], and oldest leaf $(\mathrm{OL} ; \approx 18$ th leaf below L1) using a hand-held IR thermometer. Data represent mean \pm SE $(\mathrm{n}=36)$.
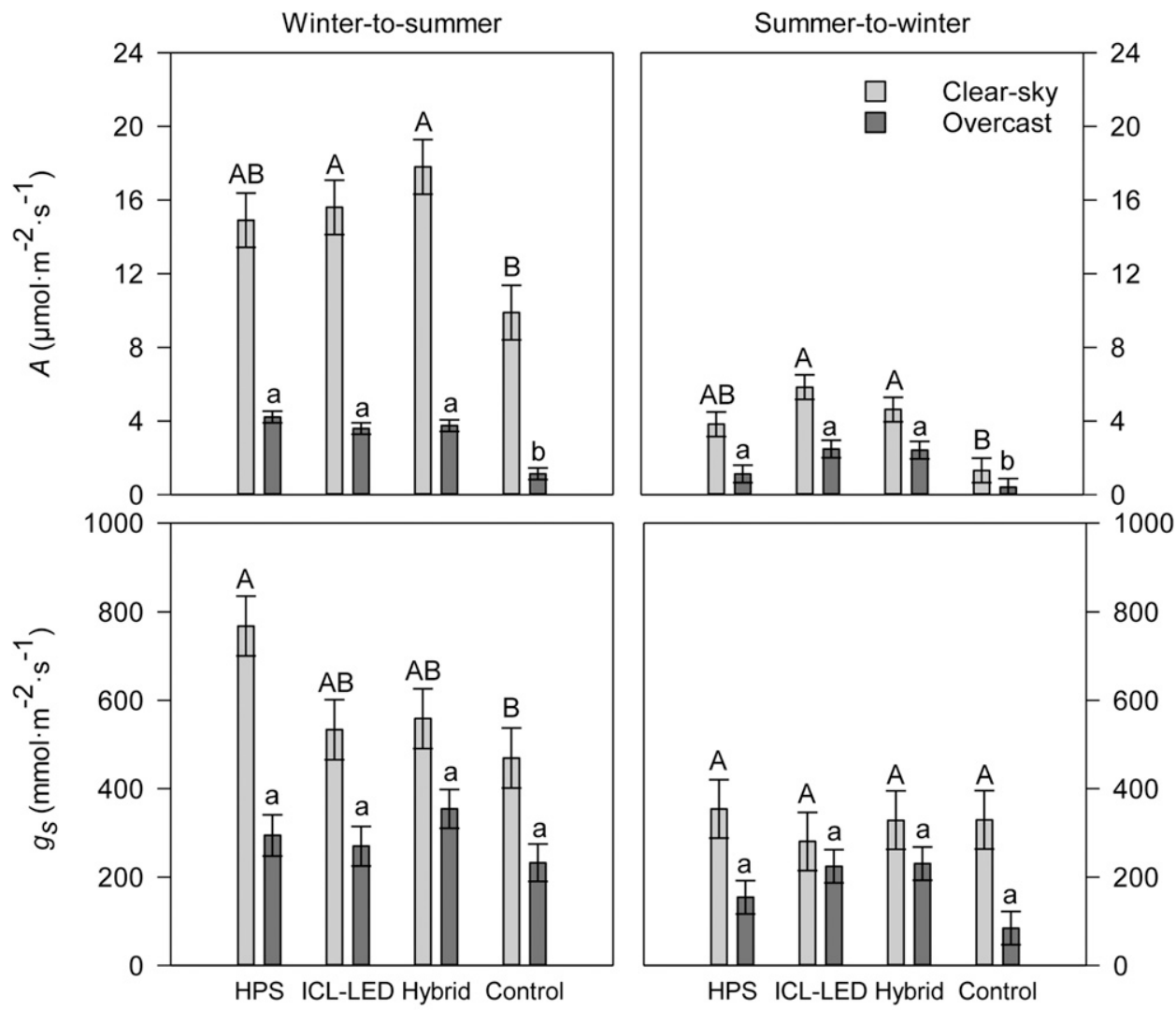

Treatment

Fig. 4. Net photosynthesis $(A)$ and stomatal conductance $\left(g_{\mathrm{s}}\right)$ measured under ambient environmental conditions for individual tomato leaves of plants grown in a greenhouse under one of four lighting treatments during opposite seasonal transition experiments in 2014. The treatments evaluated were unsupplemented controls or solar + supplemental lighting from top-high-pressure sodium (HPS) lamps, intracanopy light-emitting diode (ICL-LED) vertical towers, or hybrid lighting (top-HPS + horizontal ICL-LEDs). Data represent the average of measurements collected at three leaf layers (top, middle, or bottom leaves) within each plant. Bars (mean $\pm \mathrm{SE}, \mathrm{n}=18$ ) followed by the same font size letter are not different based on the least significant difference test $(P \leq 0.05)$. 
and tissue temperature can be cooler in the shaded understory of a crop canopy compared with the top (Frantz et al., 2000; Kitaya et al., 1998). We found that, across treatments, shoot-tip temperature was as much as $3.9^{\circ} \mathrm{C}$ warmer than leaves lower in the canopy. The similarities in tissue temperature among SL treatments, coupled with differences in temperature between top and bottom of the canopy, suggest that direct radiation from overhead solar light to the upper canopy rather than SL was responsible for differences in tissue temperature along the vertical profile of the canopy.

Chlorophyll Fluorescence. Regardless of production season, the maximum photosystem II efficiency as estimated by $F_{\mathrm{v}} / F_{\mathrm{m}}$ was lower in week 1 compared with week 2 , most likely because leaves were not yet fully expanded and, therefore, had not reached their peak photosynthetic efficiency (data not shown). However, although only significant during summer-to-winter production, $F_{\mathrm{v}} / F_{\mathrm{m}}$ declined steadily over time in both experiments (data not shown). Similarly, SL treatment effects were only found for summer-to-winter, during which $F_{\mathrm{v}} / F_{\mathrm{m}}$ was lower for plants grown without SL $(0.806)$ compared with those grown under HPS SL (0.815).

Researchers have shown that premature leaf senescence can be triggered by a negative carbon balance that typically occurs when high-light-acclimated leaves are subsequently exposed to low-light conditions (Boonman et al., 2006). Frantz et al. (2000) reported a decline in single-leaf fluorescence measurements from top-lighted compared with ICLlighted cowpea in a growth chamber. The authors attributed their results to changes over time in 1) spectral energy distribution caused by preferential absorption of specific wavelengths in the upper canopy (and subsequent filtered irradiance in the understory) and 2) decline in overall light intensity when additional leaf layers formed above index leaves being measured. It is likely that plants in our study grown under HPS lamps or without SL experienced similar changes in the radiation environment as those previously described. However, our findings showed no evidence of premature leaf senescence with top compared with ICL SL (ICL-LED or hybrid), as indicated by lack of SL treatment differences in $F_{\mathrm{v}} / F_{\mathrm{m}}$ (data not shown). It is likely that, even with SL, greenhouse-grown plants adapt to the ever-changing intensity and distribution of solar light, from which plant canopies receive radiation from all angles, depending on time of day, time of year, and leaf position within the canopy. Conversely, plants grown in controlled environments with fixed top lighting tend not to experience such sudden environmental changes. Therefore, some physiological responses (e.g., leaf senescence) of greenhouse crops may not be affected by different SL sources or positions within the canopy to the same extent as they would be in controlled environments with fixedposition sole-source lighting.

SuRVEY GaS EXCHANGE. Gas exchange at the single-leaf level is typically measured using imposed environmental conditions (within a leaf cuvette) that tend to correspond with set point environmental parameters for plant growth. However, measurements with imposed conditions do not provide enough information to understand the in situ physiological performance of plants, especially when grown in semicontrolled environments like greenhouses, with frequent fluctuations of light, temperature, and relative humidity. Instead, survey measurements portray real-time physiological activity and can further explain plant responses to lighting treatments. Overall, $A$ and $g_{\text {s }}$ were higher on clear-sky than overcast days, indicating photosynthetic activity to correspond with solar irradiance (Fig. 4).

On clear-sky days, leaves under HPS had the same $A$ as that of either LED treatment regardless of production season (Fig. 4). However, $A$ of HPS-grown leaves was also statistically similar to those grown without SL $\left(14.3 \mathrm{vs} .9 .9 \mu \mathrm{mol} \cdot \mathrm{m}^{-2} \cdot \mathrm{s}^{-1}\right.$ during winter-to-summer and 3.8 vs. $1.3 \mu \mathrm{mol} \cdot \mathrm{m}^{-2} \cdot \mathrm{s}^{-1}$ during summer-to-winter, respectively). Likewise, $A$ measured on

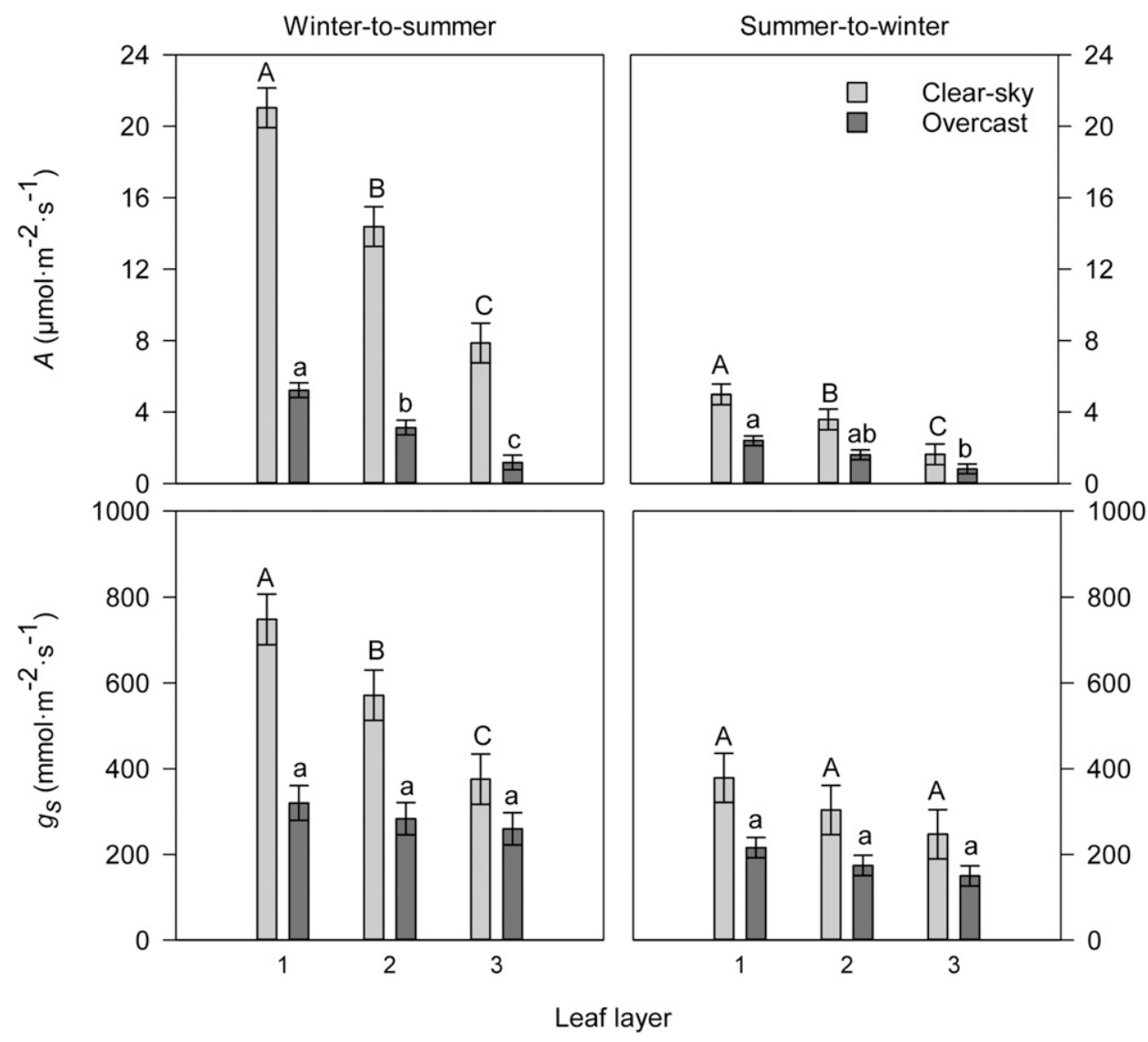

Fig. 5. Net photosynthesis $(A)$ and stomatal conductance $\left(g_{\mathrm{s}}\right)$ measured under ambient environmental conditions for individual tomato leaves of plants grown in a greenhouse during opposite seasonal transition experiments in 2014. Measurements were made on three leaf layers $(1=$ top, $2=$ middle, or $3=$ bottom $)$. Data represent the average of measurements collected from four lighting treatments: solar + supplemental lighting from top-highpressure sodium (HPS) lamps, intracanopy light-emitting diode (ICL-LED) vertical towers, hybrid lighting (topHPS + horizontal ICL-LEDs), or unsupplemented controls. Bars (mean \pm SE, $n=24)$ followed by the same font size letter are not different based on the least significant difference test $(P \leq 0.05)$. 
overcast days during both seasons was significantly higher under SL compared with control. Leaf layer effects on clear-sky and overcast days indicated that, across treatments, $A$ decreased in proportion to canopy depth (Fig. 5). During winter-to-summer, $g_{\text {s }}$ was $64 \%$ higher for leaves of plants grown with HPS compared with those grown without SL when measured on clear-sky days; no other treatment effects were found for $g_{\mathrm{s}}$ regardless of solar light intensity or production season (Fig. 4). Leaf layer effects for $g_{\mathrm{s}}$ were only significant during clear-sky days in winter-to-summer, for which $g_{\mathrm{s}}$ in LL2 and LL3 decreased by $23 \%$ and $50 \%$, respectively, from that of LL1 $\left(748 \mathrm{mmol} \cdot \mathrm{m}^{-2} \cdot \mathrm{s}^{-1}\right)$ (Fig. 5). Given the lack of SL treatment differences, and the fact that supplemental DLI was constant when survey gasexchange data were collected, the distinct reduction in $A$ and $g_{\text {s }}$ going from clear-sky to overcast conditions suggests that survey gasexchange responses were largely determined by solar radiation (and possibly by the inherent changes in ambient temperature, relative humidity, and other environmental parameters indirectly affected by solar radiation), and, to a lesser extent by SL per se (Fig. 4).

GAS EXCHANGE UNDER PREDEFINED ENVIRONMENTAL CONDITIONS. Because SL spectral effect was not significant during the winter-tosummer experiment (data not shown), data for $L_{\text {sat }}$ and $L_{\text {lim }}$ are only presented when measured under a solar spectrum. In general and across treatments, $A$ declined significantly from the top (LL1) to the bottom (LL3) of the canopy (Fig. 6). For LL1 and LL2, $A$ under $L_{\text {sat }}$ was higher for plants grown under SL compared with that for plants grown without SL, regardless of production season or SL treatment used. However, in both experiments, $A$ under $L_{\text {sat }}$ was not significantly different for lower leaves (LL3) of plants grown under HPS or those grown without SL (11.0 vs. 8.6 $\mu \mathrm{mol} \cdot \mathrm{m}^{-2} \cdot \mathrm{s}^{-1}$ in winter-to-summer and $5.3 \mathrm{vs} .5 .2 \mu \mathrm{mol} \cdot \mathrm{m}^{-2} \cdot \mathrm{s}^{-1}$ in summer-to-winter, respectively). Others have shown that when grown with top-HPS SL only, tobacco [Nicotiana tabacum (Boonman et al., 2006)] and high-wire tomato (Xu et al., 1997) have lower photosynthetic rates in the lower canopy compared with the upper canopy. The higher photosynthetic capacity measured for lower leaves grown with ICL (ICL-LED or hybrid) relative to those grown with top lighting (solar or HPS-SL) was presumably caused by providing the SL deeper into the mid and lower canopy. More leaves with positive net photosynthetic rates result in higher net canopy assimilation, which has been widely correlated with light intensity profile within the foliar canopy, and sometimes improves crop productivity (Frantz et al., 2000; Li et al., 2014; Stasiak et al., 1998). No treatment effects were recorded for $A$ under $L_{\text {lim }}$; however, leaf-layer effects indicated that for both production seasons, LL1 and LL2 had up to $23 \%$ higher $A$ than did LL3 (Fig. 6).

Similar to $A, g_{\mathrm{s}}$ was lower in LL3 compared with LL1 during both experiments measured under $L_{\mathrm{sat}}\left(618 \mathrm{vs} .840 \mathrm{mmol} \cdot \mathrm{m}^{-2} \cdot \mathrm{s}^{-1}\right.$ in winter-to-summer and 189 vs. $376 \mathrm{mmol} \cdot \mathrm{m}^{-2} \cdot \mathrm{s}^{-1}$ in summerto-winter, respectively; data not shown). Regardless of production season, no SL treatment difference was measured for $g_{\mathrm{s}}$ under $L_{\text {sat, }}$ and no leaf layer effects were recorded for $g_{\mathrm{s}}$ under $L_{\mathrm{lim}}$ (data not shown). However, in the summer-to-winter experiment, leaves from plants grown with ICL-LED or hybrid SL had up to $63 \%$ higher $g_{\mathrm{s}}$ compared with unsupplemented controls when measured under $L_{\mathrm{lim}}$ conditions $\left(357\right.$ or $326 \mathrm{mmol} \cdot \mathrm{m}^{-2} \cdot \mathrm{s}^{-1}$ compared with $132 \mathrm{mmol} \cdot \mathrm{m}^{-2} \cdot \mathrm{s}^{-1}$, respectively), whereas no differences were measured for $g_{\mathrm{s}}$ between HPS and control.

Light signaling and light-energy conversion efficiency play key roles in controlling stomatal responses of leaves (O'Carrigan et al., 2014). Blue light is known to stimulate stomatal opening 
(Lee et al., 2007; Zeiger, 2010), whereas short exposure to green light can reverse blue light-induced stomatal responses (Frechilla et al., 2000). In our study, each SL treatment affected the spectral composition of ambient light within the foliar canopy differently, either by providing a lamp-specific emission spectrum or by possibly modifying canopy architecture and/or the degree of canopy closure, thereby changing spectral energy distribution within the lower canopy. However, due to the contribution of solar light to total DLI ( $47 \%$ to $81 \%$ in winterto-summer and $60 \%$ to $17 \%$ in summer-to-winter; as calculated from solar DLI measured above canopy height), the lack of SL treatment differences in $g_{\mathrm{s}}$ under $L_{\mathrm{sat}}$ and $L_{\mathrm{lim}}$ could suggest that spectral responses for $g_{\mathrm{s}}$ may be saturated at high irradiances from broad-spectrum sunlight.

Photosynthetic light-Response CuRves. Based on the shape of the light-response curves, plants grown during winter-to-summer had a higher photosynthetic capacity than those grown during summer-to-winter (Fig. 7). Average solar DLI measured above canopy height when data were collected was 20.8 and $4.6 \mathrm{~mol} \cdot \mathrm{m}^{-2} \cdot \mathrm{d}^{-1}$ in winter-to-summer and summer-towinter, respectively (Fig. 1A). These large differences in solar DLI may account for part of the seasonal variability observed in some of the estimated and calculated parameters from light-response curves, which further explain how properties of the photosynthetic apparatus change as a function of available light (Fig. 8).

No treatment effects were found for dark respiration during winterto-summer (data not shown), whereas leaf layer did have an effect. In LL2, dark respiration was more than double that measured in LL3, but similar to that of LL1 (Fig. 8). Similar to our results, $\mathrm{Li}$ et al. (2014) evaluated hazing of greenhouse glass as an approach to increase light uniformity within a tomato canopy and found that light scattering had a significant leaf layer effect on dark respiration, but no treatment effects were found for any parameters derived from the light-response curves, including dark respiration. In contrast, in summer-to-winter, dark respiration rates for ICL-LED or hybrid SL were up to $254 \%$ or $70 \%$ higher than that for control or HPS, respectively; whereas there was no significant leaf layer effect (data not shown). Typically,

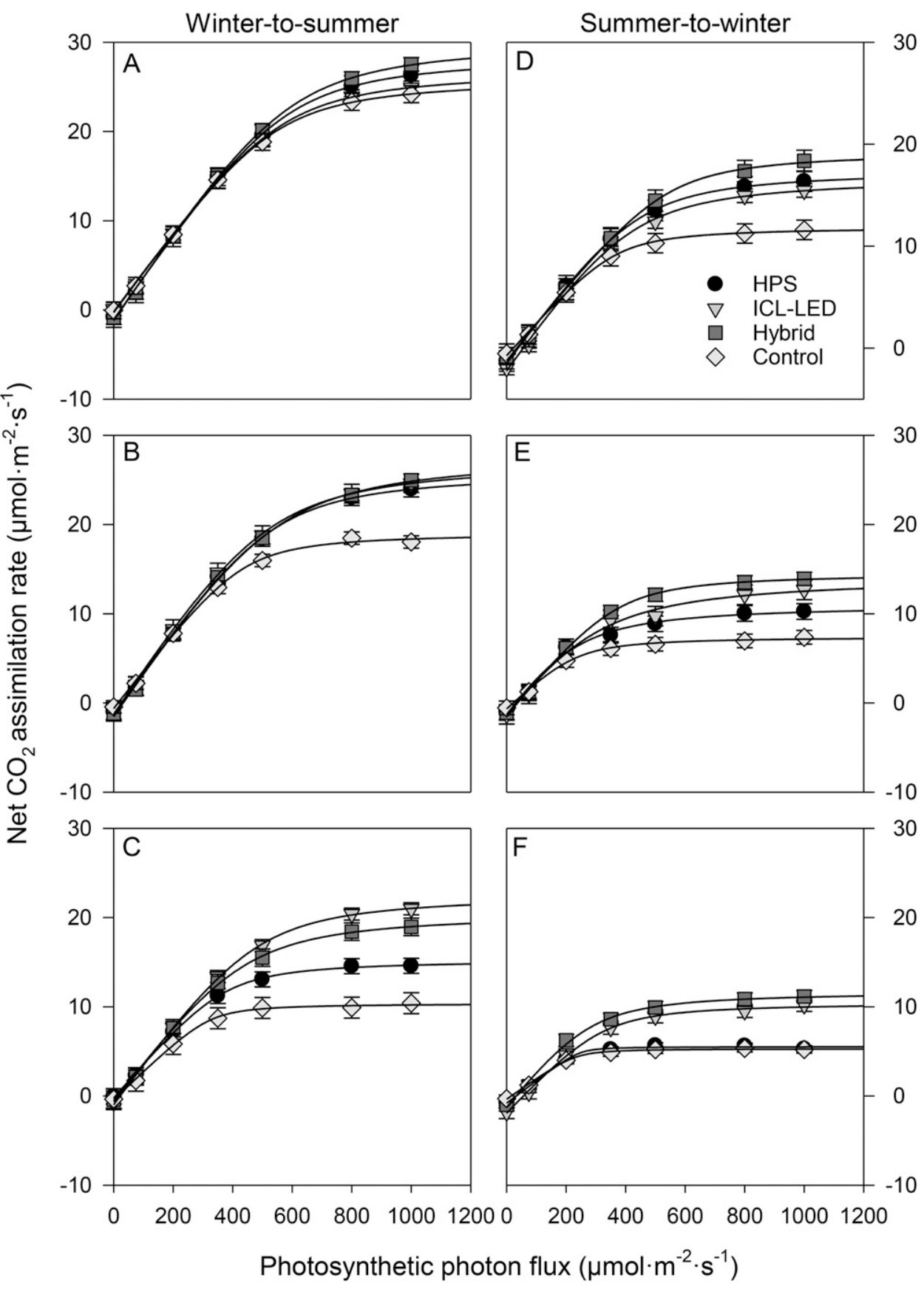

Fig. 7. Photosynthetic light-response curves for (A and $\mathbf{D})$ top, (B and $\mathbf{E})$ middle, and $(\mathbf{C}$ and $\mathbf{F})$ bottom leaves from tomato plants grown in a greenhouse under one of four lighting treatments during opposite seasonal transition experiments in 2014. The treatments evaluated were unsupplemented controls or solar + supplemental lighting from top-high-pressure sodium (HPS) lamps, intracanopy light-emitting diode (ICL-LED) vertical lighting from top-high-pressure sodium (HPS) lamps, intracanopy light-emitting diode (ICL-LE
towers, or hybrid lighting (top-HPS + horizontal ICL-LEDs). Data represent mean $\pm \operatorname{SE}(n=6)$.

top SL results in a gradual top-to-bottom canopy decline in dark respiration, most likely as an acclimation response to lightlimited conditions, which reduces metabolic activity in the lower canopy and ultimately leads to the reallocation of photoassimilates from lower leaves to growing organs (Pettersen et al., 2010). In contrast, hybrid SL has been reported to increase respiration rates in lower leaves of greenhousegrown cucumber (Pettersen et al., 2010; Trouwborst et al., 2010). Trouwborst et al. (2011) proposed that the higher dark respiration rates of lower leaves grown with hybrid SL could be 


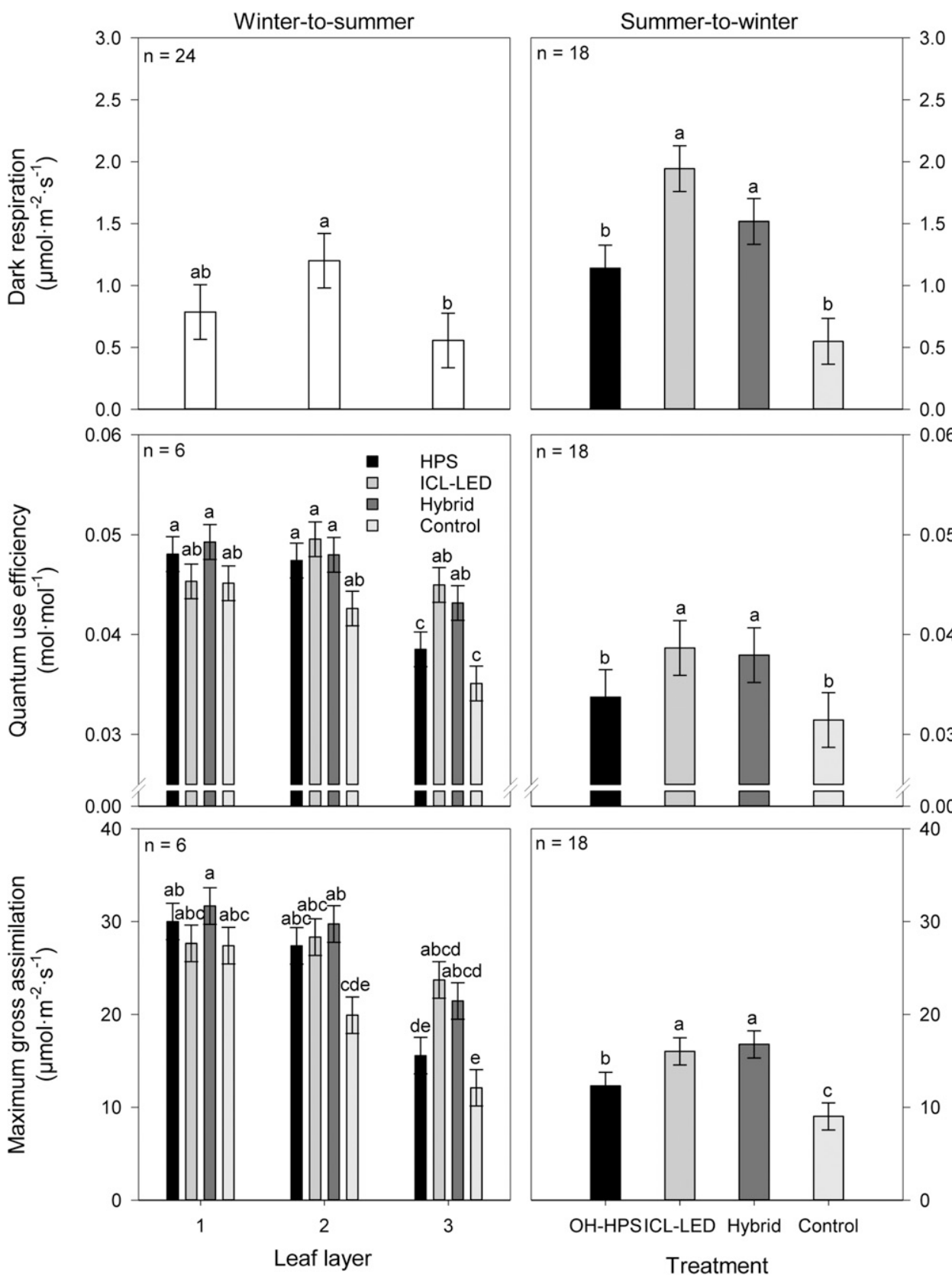

Fig. 8. Leaf gas-exchange characteristics estimated from light-response curves measured from tomato plants grown in a greenhouse under one of four lighting treatments during opposite seasonal transition experiments in 2014. The treatments evaluated were unsupplemented controls or solar + supplemental lighting from top-highpressure sodium (HPS) lamps, intracanopy light-emitting diode (ICL-LED) vertical towers, or hybrid lighting (top-HPS + horizontal ICL-LEDs). Measurements were made on three leaf layers $(1=$ top, $2=$ middle, or $3=$ bottom) for each treatment, but only significant main effects or interactions are shown. Bars (mean \pm SE) followed by the same letter are not different based on the least significant difference test $(P \leq 0.05)$.

correlated to higher $A_{\max }$, which most likely increases substrate availability for dark respiration. Similarly, McDonald (2003) stated that leaves acclimated to high light have greater dark respiration rates to sustain metabolic requirements associated with increased organelle activity from higher photosynthetic capacity (i.e., $\left.A_{\max }\right)$.

The lack of treatment effects on dark respiration during winter-to-summer could be attributed leaves being acclimated to a high solar DLI during data collection (Fig. 1A). Whereas in summer-to-winter, SL contributed most $(\approx 74 \%)$ of the total
DLI when light-response curves were measured and, thus, reflects higher dark respiration for ICLgrown leaves compared with those grown with top lighting only. The higher dark respiration of ICLgrown leaves is in agreement with observations made by Trouwborst et al. (2011) and McDonald (2003), both illustrating higher photosynthetic activity with additional lighting within the canopy.

During winter-to-summer, lightlimited quantum-use efficiency was similar along vertical leaf layers for plants grown under ICL-LED or hybrid SL, suggesting that the different leaf layers of a high-wire crop stand irradiated with intracanopy SL use low-light intensities at similar efficiencies; in contrast, quantum-use efficiency was lower in LL3 compared with the upper canopy of plants grown under HPS or without SL (Fig. 8). Similarly, quantum-use efficiency was significantly higher for ICL-grown leaves (ICL-LED or hybrid) relative to those grown with top lighting (solar or HPS-SL) across all leaf layers measured during summer-to-winter. Hogewoning et al. (2012) reported that, depending on acclimation to light-limited or light-saturated environments, light quality can significantly affect leaf quantum-use efficiency. Much of the variation in quantum-use efficiency measured across SL treatments may have been due to differences in spectral distribution, in addition to different light availability across treatments. No significant differences were recorded for $k$ in either experiment (data not shown).

Similar to quantum-use efficiency, $A_{\max }$ was not different among leaf layers for plants grown with ICL-LED or hybrid SL during winter-to-summer (Fig. 8), suggesting that the photosynthetic capacity of leaves was homogeneous across leaf layers; in contrast, we found a significant top-to-bottom decline in $A_{\max }$ for plants grown under HPS or control. Treatment effects during summer-to-winter indicate that $A_{\max }$ was higher for ICL-grown leaves (ICL-LED or hybrid) relative to those grown with HPS, and that, across leaf layers, all SL treatments had a significantly higher $A_{\max }$ than did controls. Similar to our results, others have shown that hybrid SL can maintain a higher canopy $A_{\max }$ for high-wire crops compared with top SL (Dueck et al., 2012; Pettersen et al., 2010; Trouwborst et al., 2010). Pettersen et al. (2010) explained that 
the lower top-to-bottom decline in $A_{\max }$ for plants grown with hybrid lighting is due to fewer changes over time in light intensity and quality compared with plants grown with top SL. Our findings further support the conclusion that ICL can improve the radiation environment for high-wire crop production compared with top SL by increasing overall light availability. However, the lack of SL treatment differences in yield indicates that increasing light intensity within the canopy may not be sufficient to promote productivity for greenhouse-grown tomatoes. Trouwborst et al. (2010) compared total plant production of greenhouse-grown cucumber using hybrid SL vs. HPS lamps and found that dry mass allocation to leaves was significantly higher with hybrid SL. Similar to our findings, Trouwborst et al. (2010) concluded that, although most photosynthetic parameters were significantly increased in the lower canopy, hybrid SL did not increase total biomass or fruit production relative to HPS SL. It could be that the cultivars used in our experiments had peaked their overall yield capacity in response to light; perhaps, breeding new cultivars with adaptability to ICL (e.g., higher capacity to use assimilates) has potential to increase yield responses to ICL.

Supplemental lighting increased the light-compensation point of photosynthesis relative to unsupplemented controls by at least $60 \%$ during winter-to-summer and by $89 \%$ during summer-to-winter (data not shown). It is well known that highlight-adapted leaves have higher light-compensation points than those of plants acclimated to low light, indicative of their capacity to convert more absorbed light energy into photosynthetic products (Ehleringer and Sandquist, 2010). Therefore, higher light-compensation points of plants grown with SL compared with those grown without SL is not surprising. Nonetheless, we expected a top-to-bottom decline in light-compensation point for plants grown with HPS compared with those grown with ICL SL, considering that, with top SL, middle and lower leaves within a crop foliar canopy may at times be below the light-compensation point of photosynthesis due to mutual shading. However, we found no treatment $\times$ leaf layer interactions for light-compensation point (data not shown).

Based on our results, $A$ under $L_{\text {sat }}$, quantum-use efficiency and $A_{\max }$ are good indicators of how ICL improves light availability within a high-wire tomato canopy by diminishing the top-to-bottom decline in photosynthetic activity found with top lighting only (SL or solar). Although we found a general increase in canopy photosynthetic activity from ICL-LED or hybrid SL, compared with HPS or no SL, no yield differences were recorded among SL treatments. A possible limitation to yield increases with ICL is the preferential partitioning of photoassimilates to vegetative plant parts (i.e., stems, leaves, and roots), which is in agreement with results from Trouwborst et al. (2010). An alternative explanation for the similarities in overall fruit yield is that all SL treatments provided equivalent overall DLIs. Therefore, similar yield increases relative to control are not necessarily surprising. We conclude that higher source activity does not lead to yield increases. However, as shown in this study, replacing HPS lamps with ICL or hybrid SL including LEDs has potential for significant energy savings. Given that top-LED SL has not yet been proven to increase or maintain similar yields relative to HPS, ICL, or hybrid SL with LEDs can be considered a promising SL alternative for highwire greenhouse vegetable production.

\section{Literature Cited}

Adams, S.R., K.E. Cockshull, and C.R.J. Cave. 2001. Effect of temperature on the growth and development of tomato fruits. Ann. Bot. 88:869-877.

Blacquiere, T. and J.J. Spaargaren. 2003. Necessity of supplemental lighting for year-round production of greenhouse vegetables. Acta Hort. 611:75-78.

Boonman, A., N.P.R. Anten, T.A. Dueck, W. Jordi, A. van der Werf, L. Voesenek, and T.L. Pons. 2006. Functional significance of shadeinduced leaf senescence in dense canopies: An experimental test using transgenic tobacco. Amer. Nat. 168:597-607.

Deram, P., M.G. Lefsrud, and V. Orsat. 2014. Supplemental lighting orientation and red-to-blue ratio of light-emitting diodes for greenhouse tomato production. HortScience 49:448-452.

Dueck, T.A., J. Janse, B.A. Eveleens, F.L.K. Kempkes, and L.F.M. Marcelis. 2012. Growth of tomatoes under hybrid LED and HPS lighting systems. Acta Hort. 952:335-342.

Ehleringer, J.R. and D.R. Sandquist. 2010. Photosynthesis: Physiological and ecological considerations, p. 243-269. In: L. Taiz and E. Zeiger (eds.). Plant physiology. 5th ed. Sinauer Assoc., Sunderland, MA.

Frantz, J.M., R.J. Joly, and C.A. Mitchell. 2000. Intracanopy lighting influences radiation capture, productivity, and leaf senescence in cowpea canopies. J. Amer. Soc. Hort. Sci. 125:694-701.

Frechilla, S., L.D. Talbott, R.A. Bogomolni, and E. Zeiger. 2000. Reversal of blue light-stimulated stomatal opening by green light. Plant Cell Physiol. 41:171-176.

Gajc-Wolska, J., K. Kowalczyk, A. Metera, K. Mazur, D. Bujalski, and L. Hemka. 2013. Effect of supplementary lighting on selected physiological parameters and yielding of tomato plants. Folia Hort. 25:153-159.

Gómez, C., R.C. Morrow, C.M. Bourget, G.D. Massa, and C.A. Mitchell. 2013. Comparison of intracanopy light-emitting diode towers and overhead high-pressure sodium lamps for supplemental lighting of greenhouse-grown tomatoes. HortTechnology 23:93-98. Gómez, C. and C.A. Mitchell. 2014. Supplemental lighting for greenhouse-grown tomatoes: Intracanopy LED towers vs. overhead HPS lamps. Acta Hort. 1037:855-862.

Grimstad, S.O. 1987. Supplementary lighting of early tomatoes after planting out in glass and acrylic greenhouses. Sci. Hort. 33:189-196. Gunnlaugsson, B. and S. Adalsteinsson. 2006. Interlight and plant density in year-round production of tomato at northern latitudes. Acta Hort. 711:71-75.

Hao, X.M., J.M. Zheng, C. Little, and S. Khosla. 2012. LED interlighting in year-round greenhouse mini-cucumber production. Acta Hort. 956:335-340.

Hernández, R. and C. Kubota. 2015. Physiological, morphological, and energy-use efficiency comparisons of LED and HPS supplemental lighting for cucumber transplant production. HortScience 50:351-357.

Heuvelink, E., M.J. Bakker, L. Hogendonk, J. Janse, R. Kaarsemaker, and R. Maaswinkel. 2006. Horticultural lighting in the Netherlands: New developments. Acta Hort. 711:25-34.

Hogewoning, S.W., E. Wientjes, P. Douwstra, G. Trouwborst, W. van Ieperen, R. Croce, and J. Harbinson. 2012. Photosynthetic quantum yield dynamics: From photosystems to leaves. Plant Cell 24:19211935.

Hovi, T., J. Näkkilä, and R. Tahvonen. 2004. Interlighting improves production of year-round cucumber. Sci. Hort. 102:283-294.

Hovi-Pekkanen, T., J. Näkkilä, and R. Tahvonen. 2006. Increasing productivity of sweet pepper with interlighting. Acta Hort. 711:165-170. Hovi-Pekkanen, T. and R. Tahvonen. 2008. Effects of interlighting on yield and external fruit quality in year-round cultivated cucumber. Sci. Hort. 116:152-161.

Hurd, R.G. and C.J. Graves. 1984. The influence of different temperature patterns having the same integral on the earliness and yield of tomatoes. Acta Hort. 148:547-554. 
Johnston, T.J., J.W. Pendleton, D.B. Peters, and D.R. Hicks. 1969. Influence of supplemental light on apparent photosynthesis, yield and yield components of soybeans (Glycine max L.). Crop Sci. 9:577-581.

Jokinen, K., L.E. Särkkä, and J. Näkkilä. 2012. Improving sweet pepper productivity by LED interlighting. Acta Hort. 956:59-66.

Jones, J.B., Jr. 2008. Tomato plant culture: In the field, greenhouse, and home garden. 2nd ed. CRC Press, Boca Raton, FL.

Kitaya, Y., T. Shibuya, T. Kozai, and C. Kubota. 1998. Effects of light intensity and air velocity on air temperature, water vapor pressure, and $\mathrm{CO}_{2}$ concentration inside a plant canopy under artificial lighting condition. Life Support Biosph. Sci. 5:199-203.

Korczynski, P.C., J. Logan, and J.E. Faust. 2002. Mapping monthly distribution of daily light integrals across the contiguous United States. HortTechnology 12:12-16.

Lee, S.H., R.K. Tewari, E.J. Hahn, and K.Y. Park. 2007. Photon flux density and light quality induce changes in growth, stomatal development, photosynthesis and transpiration of Withania somnifera L. Dunal. plantlets. Plant Cell Tiss. Organ Cult. 90:141-151.

Li, T., E. Heuvelink, T.A. Dueck, J. Janse, G. Gort, and L.F.M. Marcelis. 2014. Enhancement of crop photosynthesis by diffuse light: Quantifying the contributing factors. Ann. Bot. 114:145-156.

Lu, N., T. Maruo, M. Johkan, M. Hohjo, S. Tsukagoshi, Y. Ito, T. Ichimura, and Y. Shinohara. 2012a. Effects of supplemental lighting within the canopy at different developing stages on tomato yield and quality of single-truss tomato plants grown at high density. Envrion. Control Biol. 50:1-11.

Lu, N., T. Maruo, M. Johkan, M. Hohjo, S. Tsukagoshi, Y. Ito, T. Ichimura, and Y. Shinohara. 2012b. Effects of supplemental lighting with light-emitting diodes (LEDs) on tomato yield and quality of single-truss tomato plants grown at high planting density. Envrion. Control Biol. 50:63-74.

Massa, G.D., C.A. Mitchell, J.C. Emmerich, and R.C. Morrow. 2005. Development of a Reconfigurable LED Plant-Growth Lighting System for Equivalent System Mass Reduction in an ALS. 35th Intl. Conf. Environ. Systems. Rome, Italy. Soc. Automotive Eng. Tech. Paper No. 2005-01-2955.
McDonald, M.S. 2003. Photobiology of higher plants. Wiley, Chichester, England.

Nelson, J.A. and B. Bugbee. 2014. Economic analysis of greenhouse lighting: Light emitting diodes vs. high intensity discharge fixtures. PLoS One 9:1-10.

Nelson, J.A. and B. Bugbee. 2015. Analysis of environmental effects on leaf temperature under sunlight, high pressure sodium and light emitting diodes. PLoS One 10:1-13.

O'Carrigan, A., E. Hinde, N. Lu, X.Q. Xu, H. Duan, G. Huang, M. Mak, B. Bellotti, and Z.H. Chen. 2014. Effects of light irradiance on stomatal regulation and growth of tomato. Environ. Expt. Bot. 98:65-73.

Pearce, B.D., R.I. Grange, and K. Hardwick. 1993. The growth of young tomato fruit. I. Effects of temperature and irradiance on fruit grown in controlled environments. J. Hort. Sci. Biotechnol. 68:1-11.

Pettersen, R.I., S. Torre, and H.R. Gislerød. 2010. Effects of intracanopy lighting on photosynthetic characteristics in cucumber. Sci. Hort. 125:77-81.

Stasiak, M.A., R. Coté, M. Dixon, and B. Grodzinski. 1998. Increasing plant productivity in closed environments with inner canopy illumination. Life Support Biosph. Sci. 5:175-181.

Trouwborst, G., J. Oosterkamp, S.W. Hogewoning, J. Harbinson, and W. van Ieperen. 2010. The responses of light interception, photosynthesis and fruit yield of cucumber to LED-lighting within the canopy. Physiol. Plant. 138:289-300.

Trouwborst, G., A.H.C.M. Schapendonk, K. Rappoldt, S. Pot, S.W. Hogewoning, and W. van Ieperen. 2011. The effect of intracanopy lighting on cucumber fruit yield-Model analysis. Sci. Hort. 129:273-278.

U.S. Department of Agriculture. 1975. Visual aid TM-L-1. John Henry Co., Lansing, MI.

Xu, H.L., L. Gauthier, Y. Desjardins, and A. Gosselin. 1997. Photosynthesis in leaves, fruits, stem and petioles of greenhousegrown tomato plants. Photosynthetica 33:113-123.

Zeiger, E. 2010. Blue light responses: Morphogenesis and stomatal movements, p. 521-543. In: L. Taiz and E. Zeiger (eds.). Plant physiology. 5th ed. Sinauer Assoc., Sunderland, MA. 